Sādhanā Vol. 39, Part 4, August 2014, pp. 901-920. (C) Indian Academy of Sciences

\title{
Study of microwave components for an electron cyclotron resonance source: Simulations and performance
}

\author{
S K JAIN*，DEEPAK SHARMA，V K SENECHA，P A NAIK \\ and P R HANNURKAR
}

Raja Ramanna Centre for Advanced Technology, Indore 452 013, India

e-mail: skjain@rrcat.gov.in

MS received 8 July 2013; revised 14 February 2014; accepted 20 March 2014

\begin{abstract}
A high power ( $2 \mathrm{~kW}, \mathrm{CW})$ magnetron-based microwave system operating at $2.45 \mathrm{GHz}$ has been designed, tested, characterized, and used to produce plasma. The system consists of a microwave source, an isolator, a directional coupler, a threestub tuner, a high voltage break, a microwave vacuum window, and a microwave launcher. These microwave components were simulated using microwave studio software. The low power and full term characterization of the microwave system has been done using vector network analyzer. The system was tested for $2 \mathrm{~kW}$ continuous wave of microwave power using glass-water load. The microwave system has been developed to study the microwave interaction with plasma at different operation regimes (Gases: Nitrogen, argon and hydrogen; Gas pressure : $10^{-5}-10^{-3}$ mbar; Microwave power : 300-1000 W; Magnetic field: 875-1000 G) and to extract the proton beam current with hydrogen produced plasma. A plasma density $\sim 5 \times 10^{11} \mathrm{~cm}^{-3}$ and average electron temperature of $\sim 13 \mathrm{eV}$ was obtained. This article describes various aspects of the microwave system including design, fabrication, characterization and performance studies of the microwave components.
\end{abstract}

Keywords. Microwave system; microwave studio software; network analyser; electron cyclotron resonance ion source.

\section{Introduction}

Microwave systems at $2.45 \mathrm{GHz}$ have been widely used in various plasma applications to deliver the microwave power to the plasma chamber (Jain et al 2004). In this reference, very basic level microwave system development is discussed. The typical applications are: ion implantation (Matsuda \& Tanjyo 1996), etching (Miyamura et al 1982), as an ion source in accelerators (Taylor 1992), molecular beam epitaxy (Sitar et al 1990), thin film deposition (Chapman 1980), chemical vapour deposition (Nikiforov et al 1994), and sputtering (Tani et al 1998). We have

${ }^{*}$ For correspondence 
designed and developed a microwave system at $2.45 \mathrm{GHz}$ frequency and up to $2 \mathrm{~kW}$ microwave power using rectangular waveguide WR-284. The microwave system is being developed to feed the microwave power to the RRCAT-ECRIS (Jain et al 2007, 2013). A 3D-view of the microwave system with RRCAT-ECRIS is shown in figure 1 . The microwave system consists of a magnetron as a microwave generator, its power supply water cooled, waveguide components (an isolator with water cooled dummy load, a directional coupler, a three-stub tuner, a high voltage break, a microwave vacuum window, and a microwave launcher). The microwave components were studied using standard electromagnetic software and scattering parameters were optimized. The microwave system has been developed to study microwave interaction with plasma at different operation regimes (Gas : Nitrogen, argon, and hydrogen, Gas pressure : $10^{-5}-10^{-3} \mathrm{mbar}$, Microwave power : 300-1000 W, Magnetic field : 875-1000 G) and to extract the proton beam current with hydrogen produced plasma. A plasma density $\sim 5 \times 10^{11} \mathrm{~cm}^{-3}$ and average electron temperature of $\sim 13 \mathrm{eV}$ was obtained.

\section{Design considerations}

In general, a microwave system used to make an electron cyclotron resonance based plasma source consists of a microwave source, a directional coupler, an impedance matching tuner, a high voltage break, a microwave vacuum window and a microwave launcher. A standard coaxial water cooled magnetron (Model: NL10250L, Make : Philips) suitable for operating in continuous wave mode was used as a source of microwave power. The technical specifications of the coaxial magnetron are given in table 1 . In order to energize the magnetron, a DC power supply of rating negative $5 \mathrm{kV}, 1 \mathrm{~A}$ for cathode, and an AC power supply of rating $5 \mathrm{~V}, 20 \mathrm{~A}$ for filament (floating), were used. A standard water-cooled isolator was used to protect the magnetron source from any

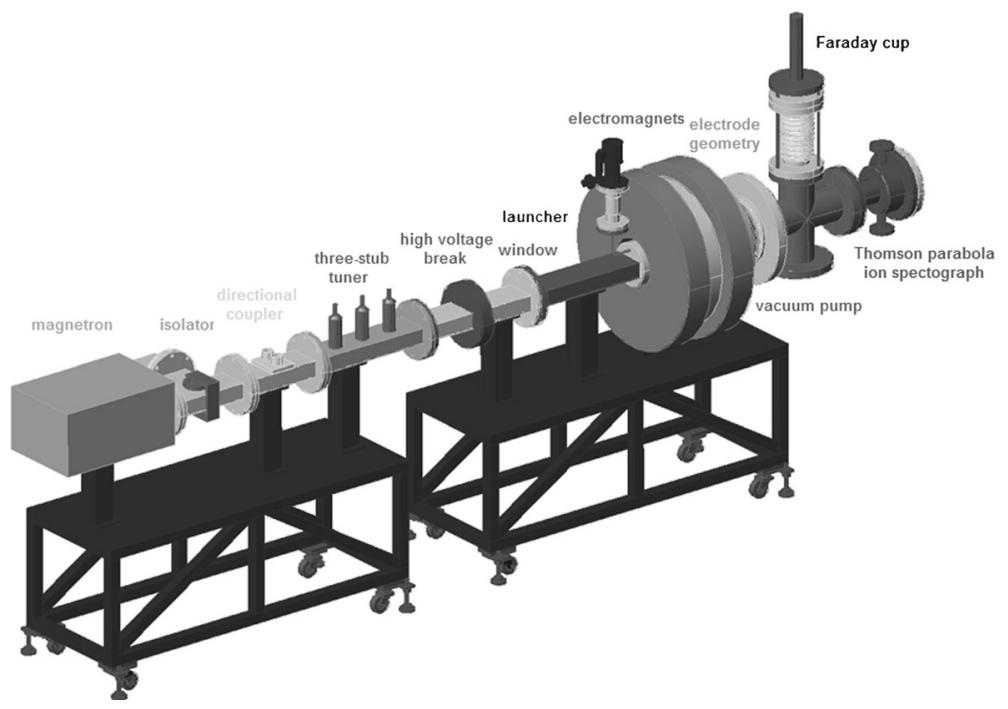

Figure 1. A 3D-view of the integrated microwave system with RRCAT-ECRIS. 
Table 1. The technical specifications of the coaxial magnetron.

\begin{tabular}{ll}
\hline System parameter & Design value \\
\hline Frequency & $2.45 \pm 0.025 \mathrm{GHz}$ \\
Output power & $2 \mathrm{~kW} \mathrm{CW}$ \\
Filament voltage & $4.6 \mathrm{~V} \mathrm{AC}$ \\
Filament current & $19 \mathrm{~A}$ \\
Cathode voltage & $4 \mathrm{kV} \mathrm{DC}$ \\
Cathode current & $725 \mathrm{~mA}$ \\
Output power & $2 \mathrm{~kW} \mathrm{CW}$ \\
\hline
\end{tabular}

reflection due to plasma impedance mismatch. A directional coupler was used for monitoring the reflected power. A tunable three-stub tuner was used as an impedance matching device. A microwave vacuum window was used for vacuum isolation to the plasma chamber. Finally, a microwave launcher was used to couple the microwave power to the plasma chamber. The plasma chamber, the microwave launcher, and the microwave vacuum window were at high voltage for extracting the proton beam. Hence, a high voltage break, which could withstand greater than $50 \mathrm{kV}$ DC continuous high voltage stress, was used for high voltage isolation.

The microwave transmission line is a coaxial line or waveguide depending upon power or frequency used. A coaxial line with $\mathrm{N}$-type connector is used where microwave power is approximately $200 \mathrm{~W}$. With a specially designed $50 \Omega$ coaxial line, microwave power is approximately $300 \mathrm{~W}$ was shown to be coupled to achieve a plasma density of $5 \times 10^{10} \mathrm{~cm}^{-3}$ (Baskaran et al 1996). Considering the maximum requirement of microwave power of $2 \mathrm{~kW}$ level for our application, we have chosen waveguide based microwave system. Although, the designated rectangular waveguide for $2.45 \mathrm{GHz}$ is WR-340, WR-284 was used since its cut-off frequency is $2.078 \mathrm{GHz}$ and it is suitable to operate at average power levels up to $6 \mathrm{~kW}$. The other reason behind using WR-284 was that, this waveguide has also been used in some other on-going projects at RRCAT. The cross-section of WR-284 is $72.14 \times 34.04 \mathrm{~mm}$ with typical wall thickness of $2 \mathrm{~mm}$, made up of oxygen-free high conductivity copper. Standard plane and choke type flanges (Harvey 1963) were used for joining of the waveguide components. The choke joint also keeps the electromagnetic field confined in the waveguide and helps to reduce the transverse microwave leakage. The microwave components were designed using the 'Microwave Studio' simulation software (http://www.cst.de). The microwave studio was used for electromagnetic field analysis and design in the high frequency range. It has three different simulation techniques. Its transient solver technique was found to be suitable for analysis of microwave components. In the simulation, the outer boundaries were chosen as perfect electric conductor. The design details of the microwave components are presented in the following sections. The design specifications of the microwave components are given in table 2. The insertion loss (the loss due to insertion of the device), and return loss (loss due to reflections) are the main design considerations for the designing the microwave components. The insertion loss $(\leq 0.05 \mathrm{~dB})$ and return loss $(\geq 20 \mathrm{~dB})$ are considerable values. For a directional coupler, the coupling factor and the directivity are also the main design consideration parameters. The coupling factor was chosen based on the availability of the microwave sensor. The directivity tells how good the input port is isolated by the isolated port and should be not less than $20 \mathrm{~dB}$. 
Table 2. The design specifications of the microwave components.

\begin{tabular}{lll}
\hline Components & System parameter & Design value \\
\hline & Frequency & $2.45 \mathrm{GHz}$ \\
Directional coupler & Microwave Power & $2 \mathrm{~kW} \mathrm{CW}$ \\
& Coupling Factor & $45 \mathrm{~dB}$ \\
& Directivity & $>20 \mathrm{~dB}$ \\
& Insertion loss & $0.0 \mathrm{~dB}$ \\
Three-stub tuner & Return loss & $5-20 \mathrm{~dB}$ \\
High voltage break & Insertion loss & $0.0 \mathrm{~dB}$ \\
& Return loss & $5-20 \mathrm{~dB}$ \\
& Insertion loss & $0.0 \mathrm{~dB}$ \\
Microwave vacuum window & Return loss & $5-20 \mathrm{~dB}$ \\
& Standoff voltage & $75 \mathrm{kV} \mathrm{DC}$ \\
& Insertion loss & $0.0 \mathrm{~dB}$ \\
& Return loss & $5-20 \mathrm{~dB}$ \\
& Microwave leakage & $<1 \mathrm{mrad}$ \\
& Vacuum leak rate & $<10^{-10}$ torr $\times$ litre/sec \\
\hline
\end{tabular}

\section{Details of microwave components}

\subsection{Directional coupler}

The directional coupler (Collin 1966; Smith et al 2003; Downs et al 2008) is a device which is commonly used for the measurement of the forward, and reflected power simultaneously. It is a four-port network (input port, transmitted port, coupled port and isolated port), and a known fraction of the microwave power flowing in a particular direction is sampled, this is used for evaluating the forward and reflected power, with knowing its coupling factor. The working principle is simple, when a wave travels from port 1 to port 2, a fixed fraction of this power appears at port 3 (i.e., waves are in phase), and there is no power appears at port 4 (i.e. waves are $180^{\circ}$ out of phase). Conversely, if the wave is travelling from port 2 to port 1 , a fraction of this signal appears at port 4 , and there is no output at port 3 . When the transmission takes place from port 1 to port 2 , the port 3 is called coupled port, and the port 4 is called isolated port.

We have designed, and developed a directional coupler (loop type, cross and bi-directional are bulky in nature) for coupling factor $45 \mathrm{~dB}$ using the microwave studio. For a directional coupler the coupling factor and directivity are also the main design consideration parameters, in addition to insertion loss and return loss. The coupling factor is fixed based on the availability of the microwave sensor and directivity (how better input port is isolated from isolated port) should be not less than $20 \mathrm{~dB}$. The schematic diagram of the directional coupler is shown in figure 2 . It has waveguide as a main line, two coupling holes for power coupling, loop plate, loop holder, and power sampling connector. The plane of the loop is kept parallel to the axis of the main line to which the loop is coupled. The length of the waveguide is $200 \mathrm{~mm}$. Based on the schematic diagram of the directional coupler, the model has been created, simulated for its low insertion loss, low return loss and good directivity using microwave studio. The directional couplers are designed to sample the power propagating in one direction. The schematic diagram of the a) loop plate, b) orientation of the loop plate with respect to direction of propagation axis, and c) model prepared in microwave studio for directional coupler is shown in figure 3.

For microwave studio simulations, the materials for all the parts were chosen to be vacuum, except the inner conductor of the ports, loops, and supporting holder. These were simulated as 


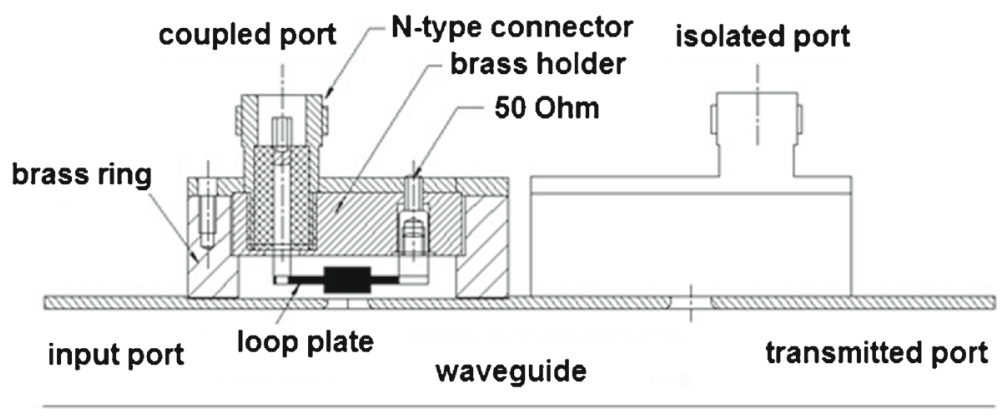

Figure 2. The schematic diagram of the directional coupler.

perfect electric conductors. The distance between the holes for microwave coupling was kept one-fourth of the guide wavelength of the operating frequency from the centre of the waveguide, to keep frequency sensitivity to minimum. A number of iterations were carried out by changing the loop, and the mid plate dimensions like, the thickness ( $\mathrm{T}: 0.5$ to $2 \mathrm{~mm}$ ) of the loop plate, the width of the loop plate ( $\mathrm{W}: 3$ to $5 \mathrm{~mm}$ ), the length of the mid plate $(\mathrm{X}: 5 \mathrm{~mm})$, the width of the mid plate (Y : 6 to $10 \mathrm{~mm}$ ), the height of the loop ( $\mathrm{H}: 0.5$ to $2 \mathrm{~mm}$ ) from the main waveguide, and theta rotations (clockwise) for the loop plate $\left(\theta_{1}\right)$ as well as the mid plate $\left(\theta_{2}\right)$. The coupling hole diameter $(\phi)$ was also varied. The S-parameters optimized with frequency for the directional coupler are shown in figure 4. The S-parameters were optimized at $2.45 \mathrm{GHz}$ frequency. From the figure, one can see that it has a very low insertion loss $0 \mathrm{~dB}$, and the return loss is about $100 \mathrm{~dB}$, the coupling factor is $45 \mathrm{~dB}$, isolation is $70 \mathrm{~dB}$ and the directivity is $25 \mathrm{~dB}$. The coupling factor and the directivity together decide the performance of the directional coupler. The variations of coupling factor, and directivity with hole-diameter for directional coupler at $2.45 \mathrm{GHz}$ frequency is shown in figure 5. It was observed in simulation that the coupling factor and isolation depends on coupling hole-diameter $(\phi)$. The directionality of coupling of power remains unchanged, since coupling and isolation are increased in symmetrical manner as it was expected, with increasing the hole-diameter.

It was observed that when the height of the loop $(\mathrm{H})$ of the main waveguide and the thickness of the loop plate $(\mathrm{T})$ were increased, the coupling $(45 \mathrm{~dB})$ was not changed. The directivity was obtained $30 \mathrm{~dB}$ for $\mathrm{T}=0.5$ and $1 \mathrm{~mm}, \mathrm{X}=5, \mathrm{Y}=6, \theta_{1}=54^{\circ}, \theta_{2}=45^{\circ}$. The loop was placed close to the waveguide $(\mathrm{H}=1 \mathrm{~mm})$ and the effect of the orientation of the loop plate, and the mid plate was studied, keeping $\mathrm{T}=1 \mathrm{~mm}, \mathrm{~W}=3 \mathrm{~mm}, \mathrm{X}=5 \mathrm{~mm}, \mathrm{Y}=6 \mathrm{~mm}$, and $\phi=$ $13.7 \mathrm{~mm}$. The results were as follows:

Case 1: When $\theta_{1}$ and $\theta_{2}$ are equal, there is no directivity except at 90 and $270^{\circ}$. In the case of $90^{\circ}$, the coupling and directivity were 43 and $20 \mathrm{~dB}$, respectively. In the $270^{\circ}$ case, the results remained the same except that the coupling port becomes isolated port and the isolated port becomes the coupled port.

Case 2: When $\theta_{1}=90^{\circ}$ and $\theta_{2}$ was changed from 0 to $90^{\circ}$, the coupling factor and the directivity were 43 and $20 \mathrm{~dB}$, respectively.

Case 3: When $\theta_{1}$ was changed from 0 to $90^{\circ}$ and $\theta_{2}=90^{\circ}$, the coupling remained almost same, but the directivity changed from 25 to $33 \mathrm{~dB}$.

Case 4: When $\theta_{1}$ and $\theta_{2}$ are not equal, some of the results for coupling factor and directivity for directional coupler are shown in table 3 . 


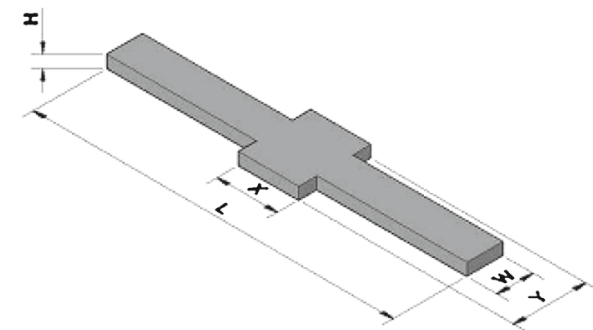

loop plate

(a)

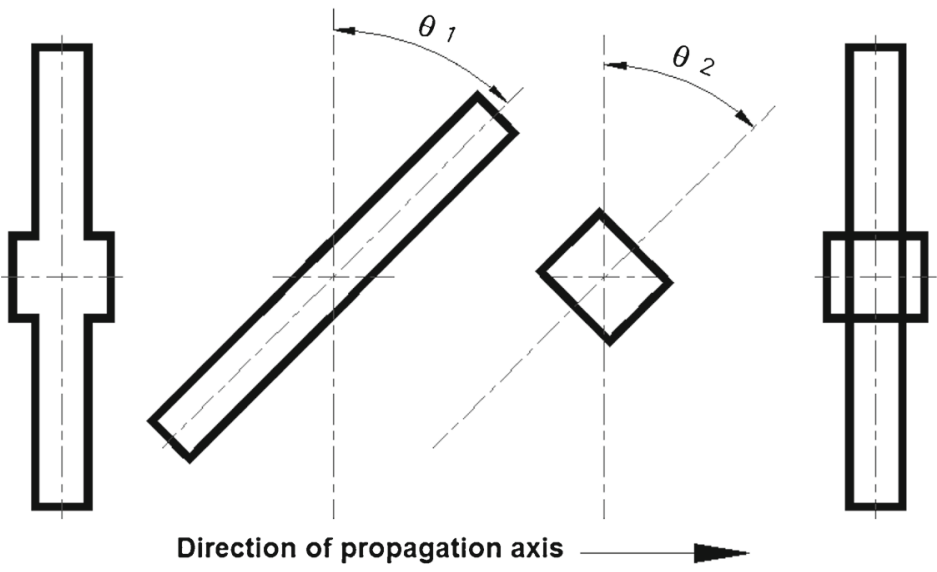

(b)

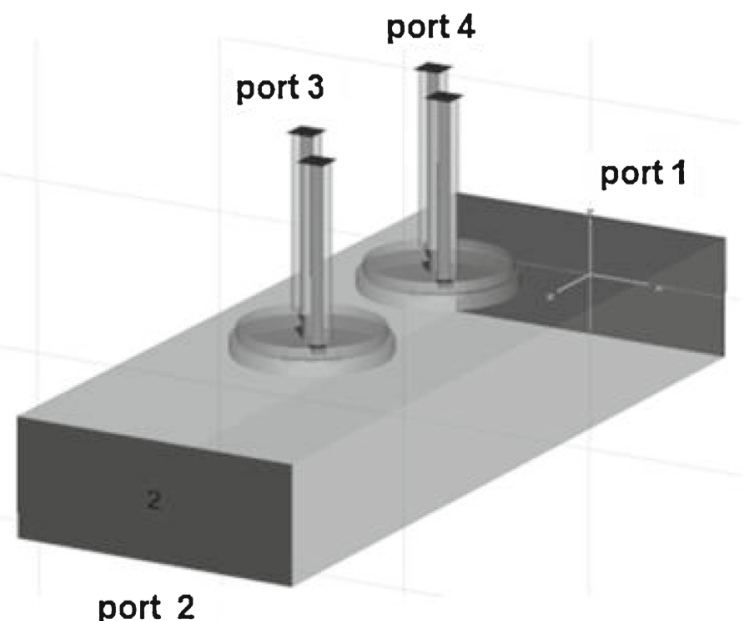

(c)

Figure 3. The schematic diagram of (a) loop plate, (b) orientation of the loop plate with respect to direction of propagation axis, and (c) model prepared in microwave studio for directional coupler. 


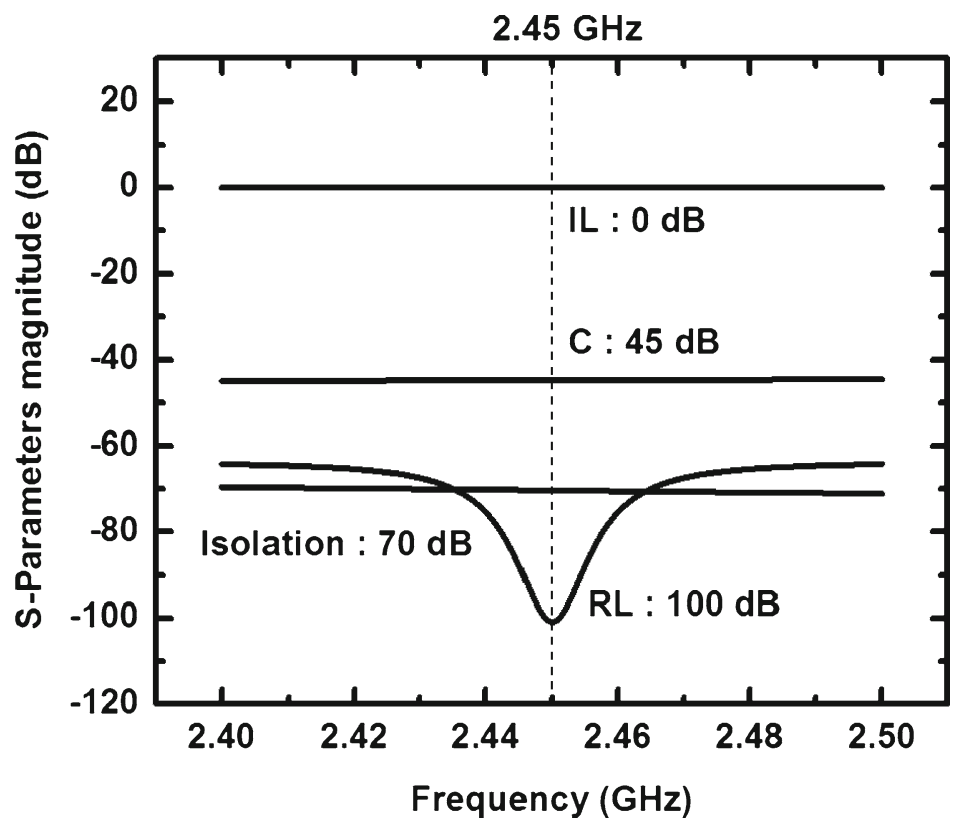

Figure 4. The S-parameters optimized with frequency for the directional coupler (IL: Insertion loss, C: Coupling factor, RL: Return loss).

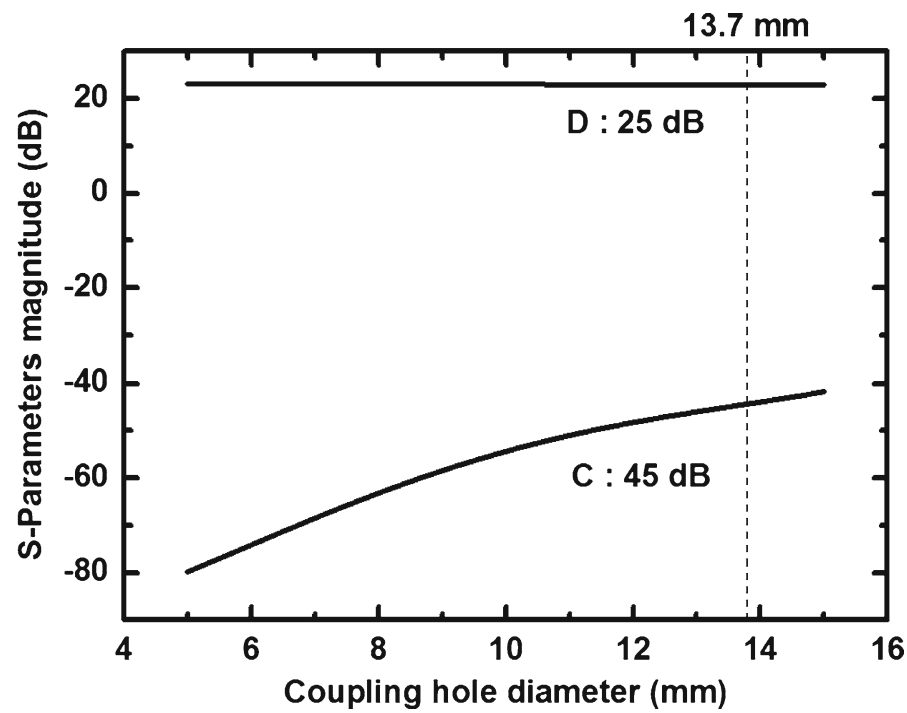

Figure 5. The variation of coupling factor, and directivity with hole-diameter for directional coupler at $2.45 \mathrm{GHz}$ frequency.

Because of symmetry the loop plate and the mid plate were rotated from 0 to $90^{\circ}$. The coupling factor was not much affected with any orientation other than longitudinal, while directivity was good when the loop plate and the mid plate were oriented at different angles, but insensitive to coupling aperture diameter. The coupling becomes minimum when loop is in transverse direction. 
Table 3. Simulated results for coupling, isolation, directivity, and return loss when $\theta_{1}$ and $\theta_{2}$ are not equal ( $\mathrm{T}=1 \mathrm{~mm}, \mathrm{~W}=3 \mathrm{~mm}, \mathrm{X}=5 \mathrm{~mm}, \mathrm{Y}=6 \mathrm{~mm}, \mathrm{H}=1 \mathrm{~mm}, \phi=13.7 \mathrm{~mm}$ ).

\begin{tabular}{llllll}
\hline$\theta_{1}($ Degree $)$ & $\theta_{\mathbf{2}}($ Degree $)$ & Coupling $(\mathrm{dB})$ & Isolation $(\mathrm{dB})$ & Directivity $(\mathrm{dB})$ & Return loss $(\mathrm{dB})$ \\
\hline 54 & 45 & 45.00 & 70.00 & 25.00 & 100.00 \\
63 & 54 & 44.11 & 77.81 & 33.70 & 100.80 \\
72 & 18 & 43.46 & 82.65 & 39.19 & 91.78 \\
63 & 18 & 44.38 & 78.46 & 34.08 & 106.30 \\
81 & 27 & 43.65 & 66.49 & 22.84 & 95.90 \\
81 & 45 & 43.59 & 69.86 & 26.27 & 103.20 \\
81 & 36 & 43.59 & 69.26 & 25.67 & 99.07 \\
\hline
\end{tabular}

For the fabrication of the directional coupler (waveguide length of $200 \mathrm{~mm}$ ), the brass rings of $\$ 35 \mathrm{~mm}$ and height $30 \mathrm{~mm}$ were fixed over both the coupling holes on broader side of the waveguide. Care was taken at the time of brazing that coupling holes remain in the centre of the brass rings. The power sensing loops were fabricated using oxygen-free high conductivity copper plate. The loops for sensing the radio frequency signal were mounted on a brass holder. A $50 \Omega$, $10 \mathrm{~W}$ chip resistance (for termination) and $\mathrm{N}$-type connector (for sampling the power) were fixed on ends of the loop. The loop holder is an independent device with respect to main waveguide, and could be freely rotated over $360^{\circ}$ for changing the orientation of the loop for coupling and directivity adjustment. The mechanical dimensions of the coupling loop play an important role in coupling and directivity performance because of the electric and magnetic fields are actually coupled through it. All the sharp edges were removed to avoid electrical arcing due to microwave power. The power sensing loops were fabricated using copper plate.

\subsection{Three-stub tuner}

Three-stub tuner (Chatterjee 1984; Collin 1966) is a device which is widely used for matching of the impedance. It has three capacitive stubs which are in parallel, and provides the variable shunt susceptance for matching the impedance. The two neighbouring stubs $(1+2$ or $2+3)$ in combinations are used at a time for matching; each pair covered about half of the complete matchable area in the smith chart. This device is commonly used for matching of the plasma impedance to the waveguide impedance. The impedance of the plasma is inhomogeneous in nature because of the magnetic field gradients and recombination near the walls of the plasma chamber. The impedance of the plasma is dynamical in nature, and depends on the gas pressure, magnetic field, microwave power, operating conditions, etc. Hence, it is required to match the impedance of the microwave transmission line to the impedance of the plasma, in order to minimize the microwave reflections and to prevent the magnetron and microwave vacuum window from damage due to back-streaming of electrons. Here, we have used three-stub tuner as impedance matching device. We have designed, and developed a three-stub tuner as variable impedance matching device. It matches the modulus and phase of the incoming wave in order to match the plasma impedance by adjusting the depth of the stubs (small sections of transmission lines which are connected in shunt or series to the main line for impedance matching). The schematic of shunt connected stub as a three-stub tuner is shown in figure 6 a.

For understanding the behaviour of the three-stub tuner, it was simulated in microwave studio, the medium for waveguide was chosen as vacuum, and material for simulation of shunt stubs was perfect electric conductor. It consists of three-stubs mounted on the broad wall of the waveguide at equal distance (i.e., three-eighth of the guide wavelength) to keep the frequency sensitivity 


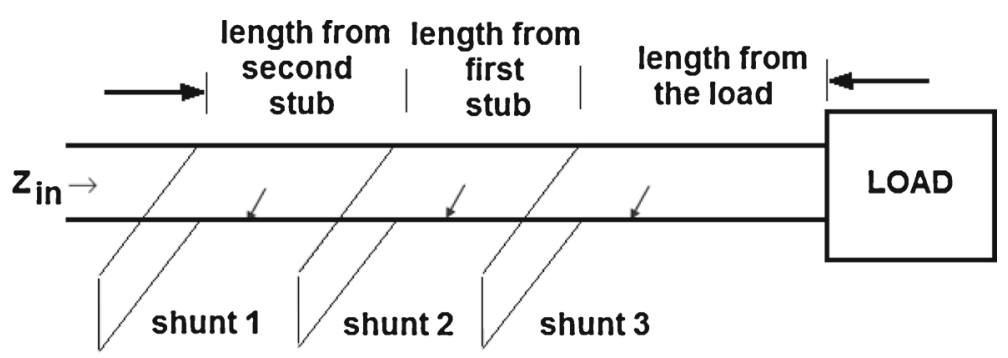

(a)

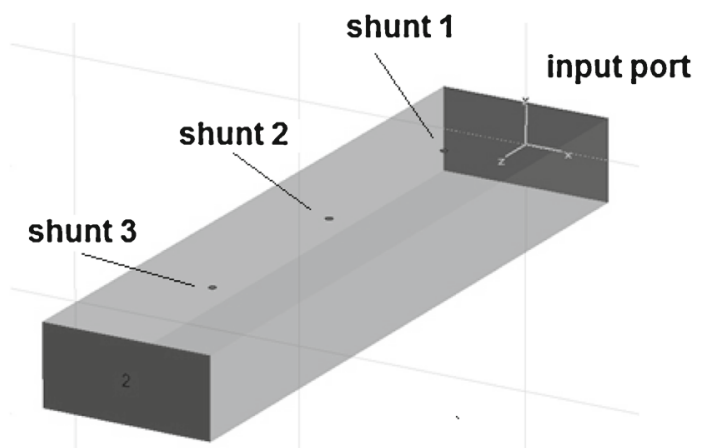

output port

(b)

Figure 6. The schematic diagram of shunt connected as a three-stub tuner, (a), and (b) model prepared in microwave studio for three-stub tuner.

to minimum and are manually guided (in or out). The length of the waveguide for three-stub tuner is $300 \mathrm{~mm}$. The effects of shunt stubs were checked with microwave studio for its tuning range by varying the depth of penetration of the shunt stubs. It has been observed that shunt capacitive susceptance changes for wide range which supports to minimize the reflected power, and matched the impedance of the plasma as a load. The model prepared in microwave studio for three-stub tuner is shown in figure $6 \mathrm{~b}$. The tuning procedure is as follows: when microwave line is energized, these stubs are manually actuated in and out, and reflected power is monitored to make it minimum. The stubs can penetrate maximum two-third height of the waveguide. During penetration, it provides the shunt capacitive susceptance, to match the impedance of the plasma. Smooth movement is required at the time of tuning to avoid any electrical arcing.

\subsection{High voltage break}

High voltage break (Taylor \& Mouris 1993; Gammino et al 1999) is a crucial component which is commonly used for the high voltage isolation of the microwave system to the plasma chamber. The plasma chamber remains at high voltage for extracting the ion beam at required energy. It is required to keep the microwave at ground potential during the operation of the source and for tuning the reflected power. We have designed, and developed a high voltage break to stand-off the voltage of $75 \mathrm{kV}$ DC (50 kV DC is required for second Phase of the development). The design of the high voltage break should have good mechanical rigidity, low microwave loss, with stand-off 
high voltage isolation, and low microwave radiation leakage to environment. It was simulated using microwave studio for microwave point of view (low microwave loss), with the proper thickness of modelling of the insulator to stand-off $75 \mathrm{kV} \mathrm{DC}$ voltage. It has two waveguide of length $150 \mathrm{~mm}$ both sides with its inside material chosen as vacuum, and the thickness of waveguide chosen as perfect electric conductor. An insulator was sandwiched in between for finding its scattering parameters. The complete assembly was enclosed in a rectangular box with material as air to see the real effects under actual environment. The materials normally used for low loss for microwave, good mechanical strength and high voltage isolation are Teflon, highdensity polyethylene and polypropylene, which are commercially available. Here, we have used Teflon as a high voltage isolation material and numbers of iteration were carried out to get the proper thickness of Teflon to achieve the minimum return loss and insertion loss using microwave studio. The S-parameters optimized with frequency for high voltage break are shown in figure 7. It is noted from the figure, that the return loss is $40 \mathrm{~dB}$ and insertion loss is $0.08 \mathrm{~dB}$ for $7.35 \mathrm{~mm}$ Teflon thickness at $2.45 \mathrm{GHz}$ frequency. The insertion loss is higher than the desired one, this may be due to microwave absorption property of the Teflon. The device was backed at $120^{\circ} \mathrm{C}$ for two hours, for the settlement of high voltage epoxy under vacuum environment. The high voltage insulation was tested using high voltage Megger (Model: 220123-47, Make: M/s Megger, Biddle, England). It works satisfactorily up to $75 \mathrm{kV}$ DC isolation with no leakage current.

\subsection{Microwave vacuum window}

Microwave vacuum window (Marcuvitz 1951; Ganguli et al 1989; Taylor \& Wills 1991; Taylor 1992; Baskaran et al 1992a, b; Baskaran 1997) is a device which is widely used for the isolation

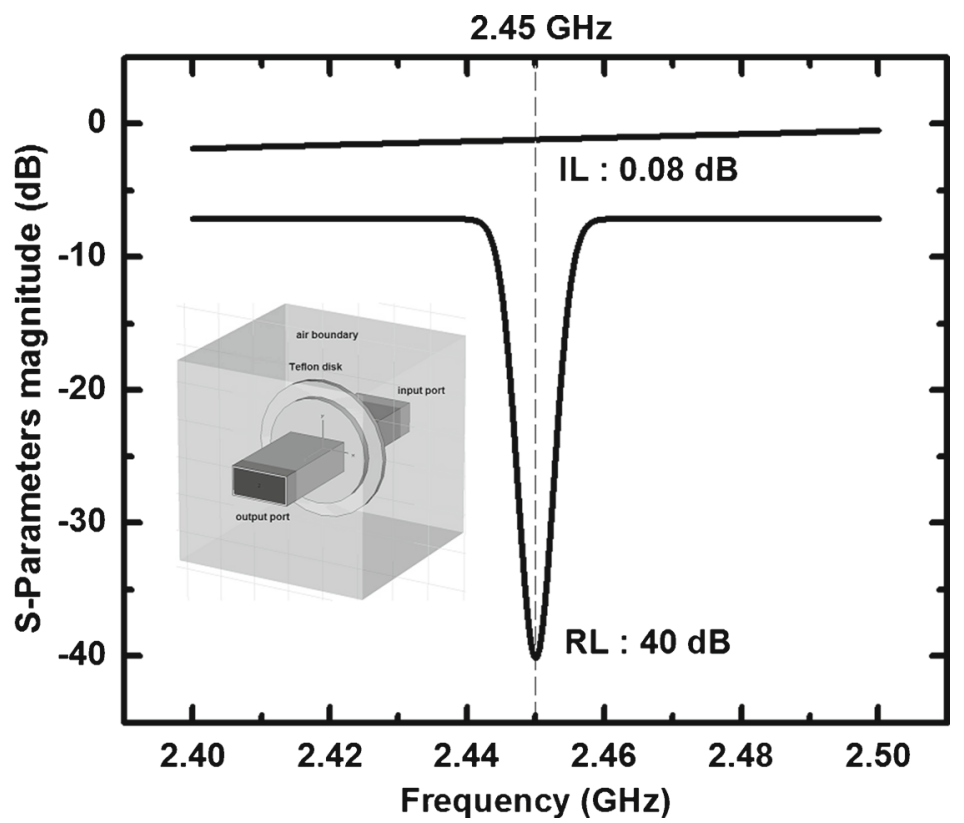

Figure 7. The S-parameters optimized with frequency for high voltage break (inset: model of high voltage break prepared in microwave studio). 
of microwave system to the plasma chamber which is under vacuum. A microwave vacuum window is commonly uses as a single/double/triple layer of mica, quartz, Teflon, alumina, aluminum nitride, boron nitride or combinations of these. The properties of these materials are considered as a design criteria. It should have high dielectric strength, low dielectric loss, high coefficient of thermal expansion, low thermal conductivity, high mechanical strength, and should allow the microwave power propagation with low loss. The thickness of the window material should be chosen in such a way that it can sustain the force of back-streaming of high energetic electrons, and stop the plasma flow back to the microwave source (i.e., magnetron). Sometimes, it may get punctured due to excessive heating, leading to the failure of the ion source. The use of multilayered window increases the cost as well as complexity for fabrication. We have designed and built a single layer window at $2.45 \mathrm{GHz}$ frequency. For constructing the geometry in microwave studio for simulation (shown as inset under figure 8a), the length of waveguide was chosen to be $100 \mathrm{~mm}$. Very thin capacitive obstacles were used for impedance matching on both sides of the flange. Quartz was chosen as the window material, since it is cheap and easily available. In the simulations, the thickness of the window material was varied from 0.1 to $10 \mathrm{~mm}$. To check the validity of the design and model, it was first run with zero thickness to make sure that same results are obtained as achieved with only standard flanges (return loss, insertion loss). The variation of return loss, and insertion loss a) with frequency, and b) with quartz thickness for microwave vacuum window is shown in figure 8. The simulation shows that for the $6 \mathrm{~mm}$ thickness of quartz plate, the return loss is $75 \mathrm{~dB}$ and insertion loss is $2.5 \mu \mathrm{dB}$, close to zero. Normally, the bandwidth is defined in terms of 3 or $1 \mathrm{~dB}$ fall in output power over the frequency, for a constant input power. However, in our case, the insertion loss being flat over a large frequency range (wider than the range over which measurements were performed). Hence the bandwidth is defined in terms of the frequency where the return loss crosses $20 \mathrm{~dB}$ level. With this definition, the transmission bandwidth, was $80 \mathrm{MHz}$. A rectangular quartz plate was fixed using conductive glue. The window was helium leak tested using a helium mass spectrometer and leak rate was found to be less than $10^{-10} \mathrm{mbar}$ liter/sec. The outer periphery was covered using grounded copper strip to avoid any transverse leakage of the microwave power.

\subsection{Microwave launcher}

Microwave launcher is a device which is used to couple the microwave power to the plasma chamber. There are various devices used as a microwave launcher viz. coaxial line (Sakudo et al 1977), open ended waveguide (Krestschmer et al 1980), horn, slotted and helical antenna (Baskaran et al 1992a, b), ridged and tapered waveguide (Sherman et al 1998; Celona et al 1998, 2000). The performance of plasma source viz. plasma density, electron temperature and hence the ion current can be improved significantly by proper selection and design of the microwave launcher. Here, we have studied using microwave studio a tapered waveguide and a ridged waveguide. These devices are widely used now-a-days as a microwave launcher because of its ease of fabrication, low cost, and wide bandwidth. Both launchers have a special property that they gradually match the impedance of the microwave transmission to the impedance of the plasma, which leads to a low reflection and a low higher order mode coupling. Other devices were avoided because of space limitations. The details of the two launchers are described in the following sections.

3.5a Tapered launcher: We have designed and developed a tapered launcher to feed the microwave power to the plasma chamber. For simulations of tapered launcher in microwave 


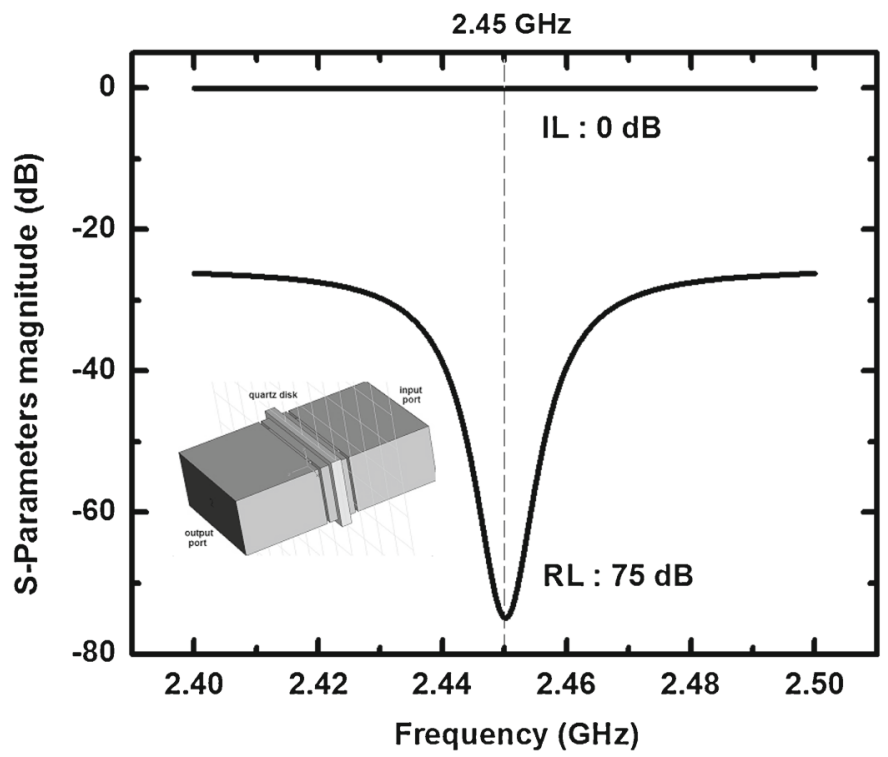

(a)

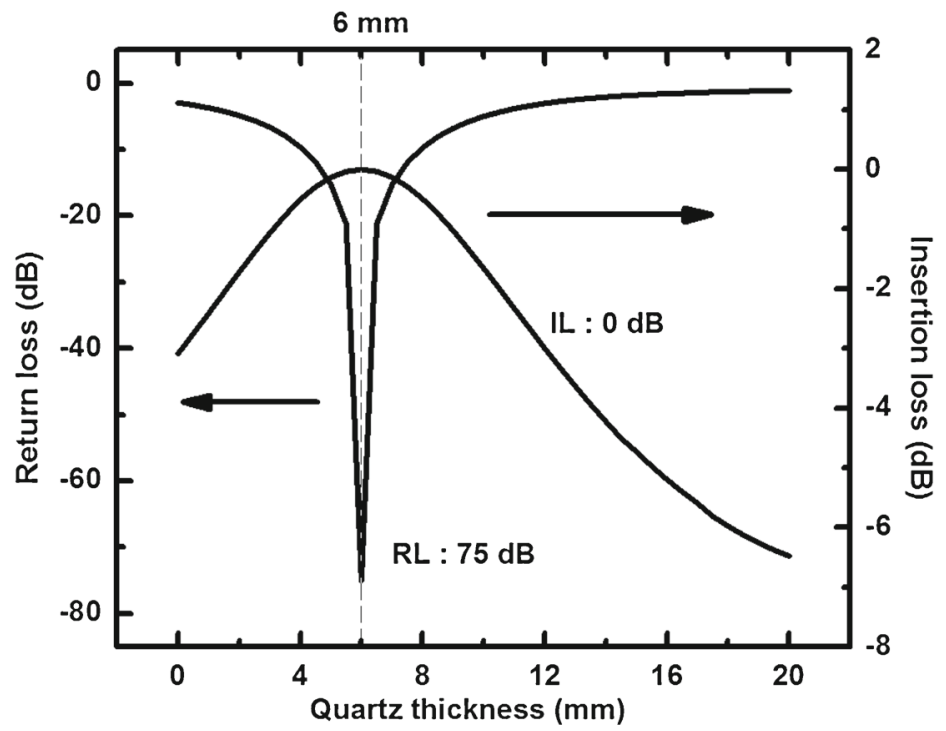

(b)

Figure 8. The variation of return loss, and insertion loss (a) with frequency, and (b) with quartz thickness for microwave vacuum window. (inset: in figure $8 \mathrm{a}$ has model of microwave vacuum window prepared in microwave studio).

studio, two bricks of length $50 \mathrm{~mm}$ of dimensions $72.14 \times 34.04 \mathrm{~mm}$ (matching with waveguide dimension) and $72.14 \times 10 \mathrm{~mm}$ (achieved with microwave studio simulation), with wall thickness $2 \mathrm{~mm}$, at a distance of one guide waveguide length. In waveguide the electric field 
depends on the narrow dimensions of the waveguide. In microwave studio simulation, vacuum was chosen as the inner material and a perfect electric conductor for the wall thickness. Now, the opposite faces of the brick were picked and then loft command in microwave studio was used to form tapered launcher. Thus, by changing the narrow dimensions of the waveguide, the increase in the intensity of the electric field was observed in the simulation using microwave studio. It has been observed that the intensity of the electric field becomes almost doubled when narrow dimensions reaches $10 \mathrm{~mm}$. This electric field enhances the plasma density, since the power is directly proportional to the square of the intensity of the electric field. The optimized electric field distribution a), and b) variation of electric field with the height of waveguide for a tapered launcher simulated with microwave studio is shown in figure 9. The performance of coupling microwave power into the plasma was found to be very good, that most of the incoming power was coupled to the plasma chamber and very low reflected power was noticed. The return loss $23 \mathrm{~dB}$ and the insertion loss close to $0.02 \mathrm{~dB}$ at $2.45 \mathrm{GHz}$ was obtained with the simulation.

3.5b Ridged waveguide launcher: A ridged waveguides with three/four sections has been widely used as a microwave launcher in different laboratories like Chalk River Laboratory, Trips, Silhi, MIDAS, VIS, ALISES, and Spiral2. Like a tapered waveguide, a ridged waveguide also matches the impedance (progressively reducing with the ridge gap) from the source waveguide impedance to the plasma impedance, which is of the order of 150-100 $\Omega$ (http:// www.Ins.infn.it). A ridged waveguide concentrates the electric field near the source axis, while in a standard waveguide it is distributed in a sinusoidal form along the larger dimensions. It has a wider bandwidth. This reduces the necessity of high power level of the microwave radiation for the extraction of higher ion beam current and also reduces the requirement of water-cooling required for the plasma chamber, thereby enabling operation of the source in continuous mode for several hours. The magnitude of the electric field intensity depends on the number of ridged sections. The dimensions and impedance of the ridged sections evaluated as binomial matching transformers (Pozar 2005) as

$$
\frac{Z n+1}{Z n}=\exp \left[2^{-N} C n^{N} \ln \frac{Z_{L}}{Z_{0}}\right],
$$

where $\mathrm{n}$ is the number of the ridged section, $\mathrm{N}$ is the total number of the ridged sections, and $\mathrm{C}_{\mathrm{n}}^{\mathrm{N}}$ is the binomial coefficients i.e., $\mathrm{N}$ ! / (N-n)! $\mathrm{n}$ !. Here, the length of each sections is fixed and is equal to quarter guide wavelength. The optimized variations of the return loss, the insertion loss for ridged waveguide with frequency range between 2.4 and $2.5 \mathrm{GHz}$ is shown in figure 10 . It is noted from the figure that, the return loss is better than $38 \mathrm{~dB}$ and insertion loss is close to $0 \mathrm{~dB}$ at $2.45 \mathrm{GHz}$ frequency. The electric field distributions in a) a standard waveguide, and b) a ridged waveguide are shown in figure 11. It is noted from the figure that, standard waveguide has maximum electric field amplitude of about $757 \mathrm{~V} / \mathrm{m}$ along the Z-axis and the ridged waveguide has $1574 \mathrm{~V} / \mathrm{m}$ at output port for a ridge width of $12.5 \mathrm{~mm}$. This ridged waveguide with four sections (ridge gaps: $31,20,15.5$ and $10 \mathrm{~mm}$, and ridge width : $12.5 \mathrm{~mm}$ ) was coupled to the resonant plasma chamber. It was observed that the electric field is about $2757 \mathrm{~V} / \mathrm{m}$ at the centre of the plasma chamber and is distributed uniformly. The electric field intensity in the horizontal plane of the ridged waveguide coupled with the plasma chamber is shown in figure 12 . 


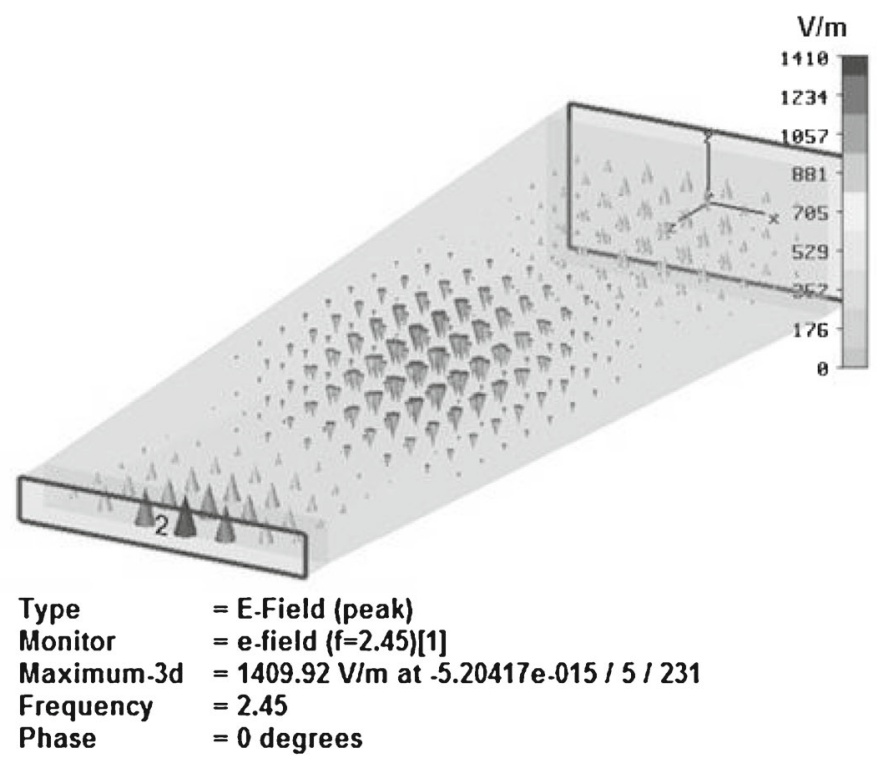

(a)

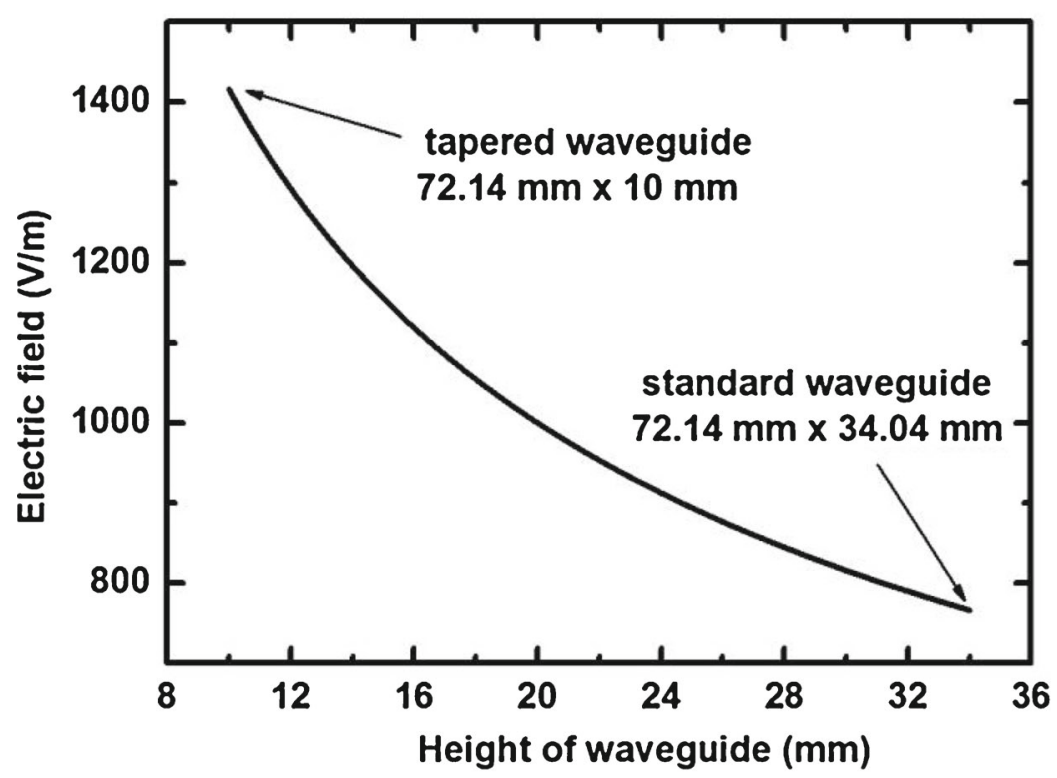

(b)

Figure 9. The optimized electric field distribution (a), and (b) variation of electric field with the height of waveguide for a tapered launcher simulated with microwave studio.

\section{Characterization of microwave components (Montgomery 1947; Ginzton 1957)}

Low power characterization of the microwave components was carried out using a network analyser (Make : M/s Agilent Technologies Pvt. Ltd., Model : E5071 ENA series with electronic-cal 


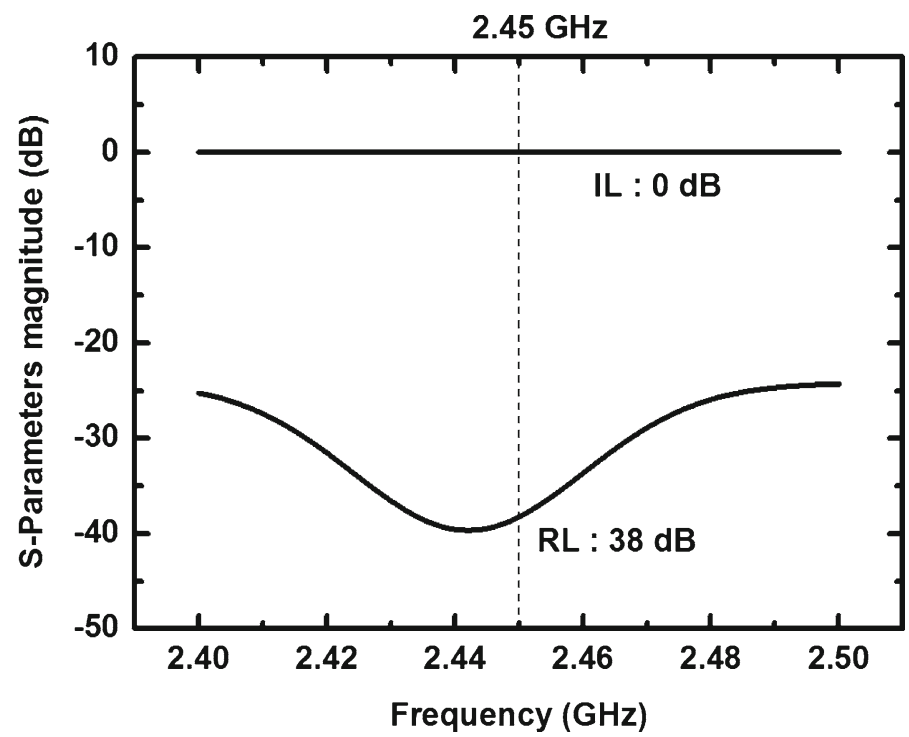

Figure 10. The optimized variations of the return loss, the insertion loss for the ridged waveguide with frequency range between 2.4 and $2.5 \mathrm{GHz}$.

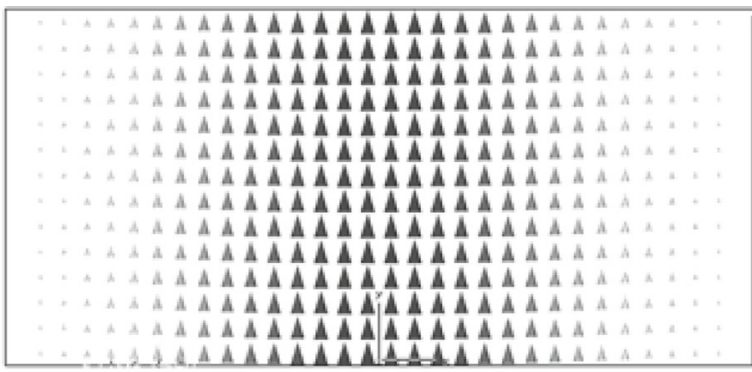

(a)

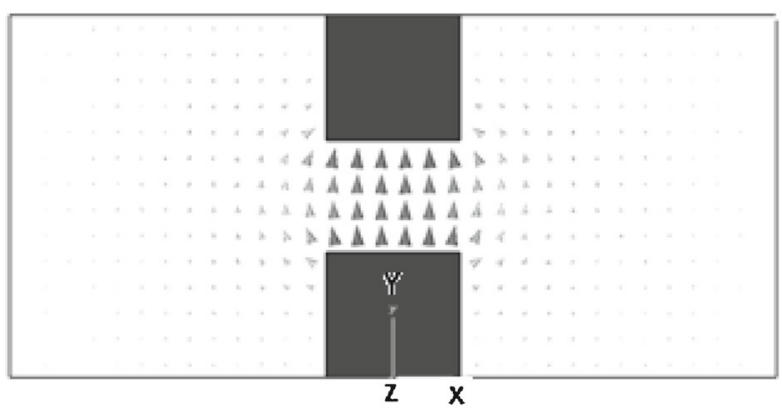

Vim

1574

1377

1180

984

787

590

393

197

(b)

Figure 11. The electric field distribution in, (a) standard waveguide, and (b) ridged waveguide. 


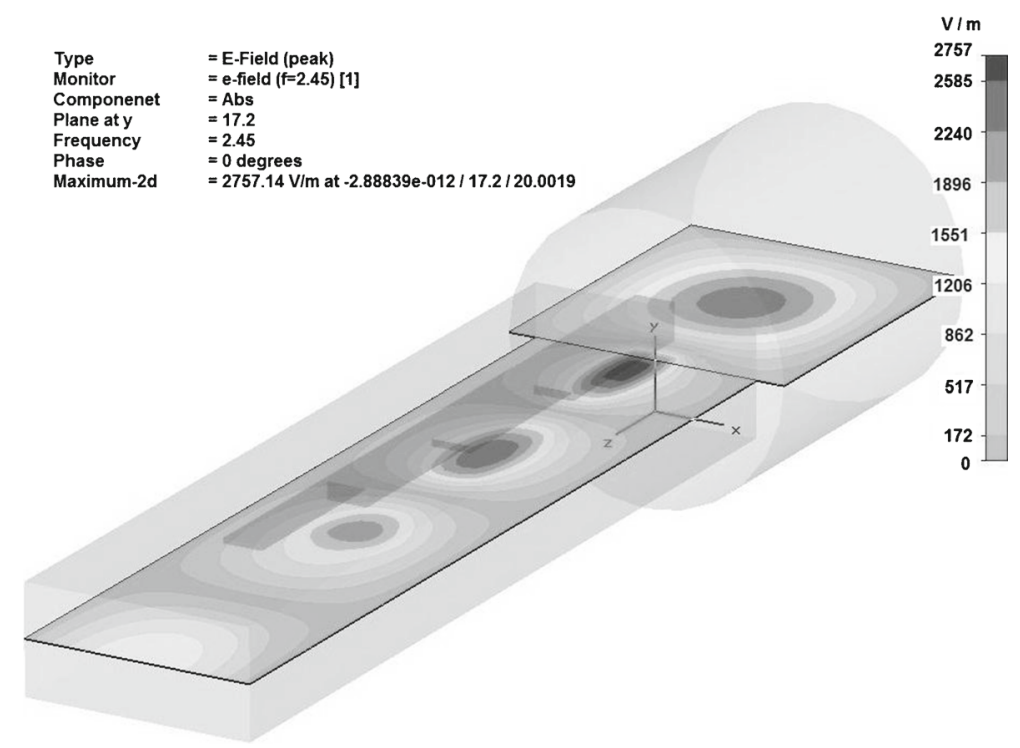

Figure 12. The electric field intensity in the horizontal plane of the ridged waveguide coupled with the plasma chamber.

kit, N4431-60004) for validating design procedure. The full term characterization (two port scattering parameters viz. S11, S21, S12 and S22) was carried out for frequency 2.4 to $2.5 \mathrm{GHz}$ (marker is placed at $2.45 \mathrm{GHz}$, bandwidth $100 \mathrm{MHz}$ ), with various standards of network analysers. The measured results of a) directional coupler, b) three-stub tuner full IN, c) three-stub tuner full OUT, d) high voltage break, and e) microwave vacuum window using network analyser are shown in figure 13 . The measurement inaccuracy in characterization was $10 \mathrm{mdB}$. The measurement accuracy in the results could be maintained by routinely characterization of the microwave components. The mechanical error of fabrication, etc. could not be taken into account in the microwave studio simulation. Hence, some differences in simulations and measurements results were expected. The results are summarized for directional coupler are as follows: the insertion loss for the device is close to $0.06 \mathrm{~dB}$, the return loss is $37 \mathrm{~dB}$ (measured) and $100 \mathrm{~dB}$ (figure 4, software, assumes ideal conditions), the coupling factor $44.5 \pm 0.5 \mathrm{~dB}$, the directivity is $25.5 \pm$ $0.5 \mathrm{~dB}$ at $2.45 \mathrm{GHz}$ frequency, except the return loss, the measured results are close to optimized results. This validates the design procedure of directional coupler.

For the low power measurements of the three-stub tuner, two cases were studied i.e., all stubs are FULL IN and FULL OUT to see the impedance variations on Smith chart. One can see from the figure $13 \mathrm{~b}$, when all stubs are FULL IN, the insertion loss is $32 \mathrm{~dB}$ and return loss is $0.3 \mathrm{~dB}$. In this case, the microwave power is severely reflected which causes the more insertion loss. It is noted from the figure 13c, when all the stubs are FULL OUT, the measured insertion loss is $0.3 \mathrm{~dB}$ and remains unchanged up to $2.46 \mathrm{GHz}$, whereas the return loss is close to $26 \mathrm{~dB}$ up to $2.46 \mathrm{GHz}$, and beyond this it increases with increasing frequency. The behaviour of the figure is as expected, since the obstacles of the stubs produces the standing wave patterns during the propagation of the microwaves which causes the losses of microwave power. Effectively it covers the wide range of insertion loss 0.3 to $30 \mathrm{~dB}$ (due to obstacles of stubs, simply comprise for impedance matching) and return loss is 0 to $25 \mathrm{~dB}$. The insertion loss was brought down to less than $0.3 \mathrm{~dB}$ with the multiple combinations of stubs during the operation of the source (matched 


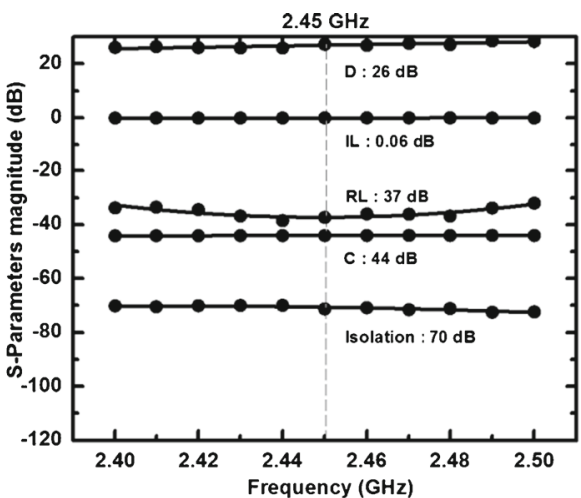

(a)

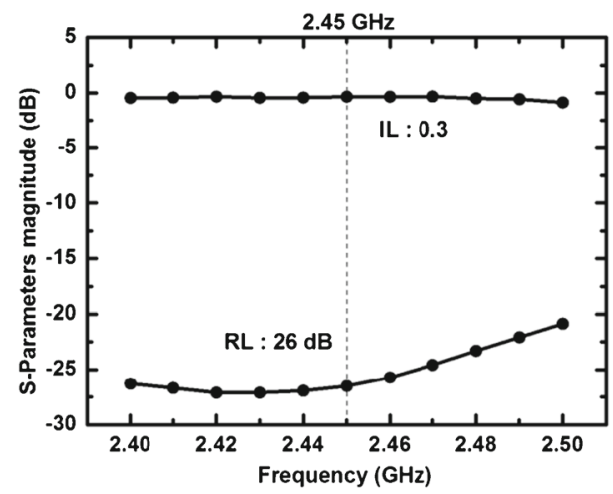

(c)

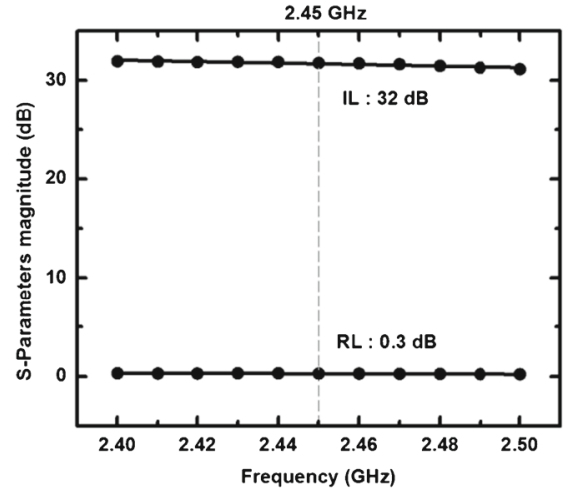

(b)

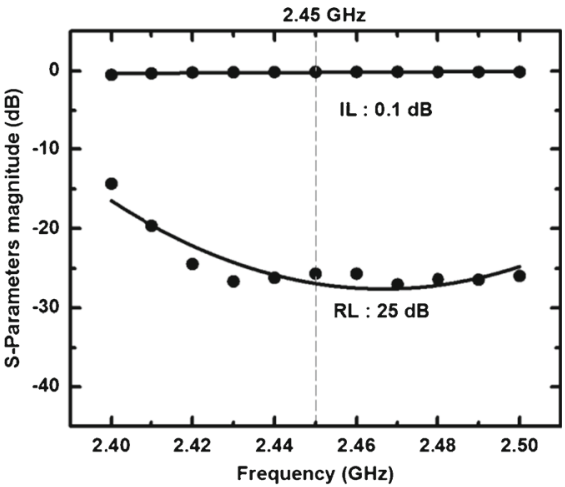

(d)

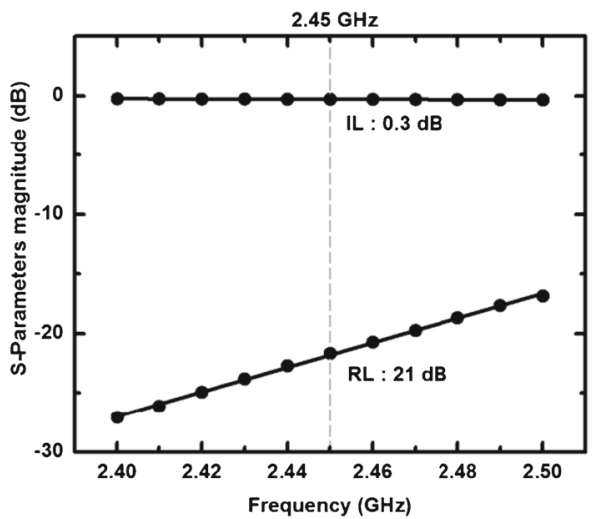

(e)

Figure 13. The measured results of (a) directional coupler, (b) three-stub tuner full IN, (c) three-stub tuner full OUT, (d) high voltage break, and (e) microwave vacuum window using network analyser (the solid curve is for visual aid only). 
condition i.e., low reflected power). It is noted from the figure $13 \mathrm{~d}$ (high voltage break), that the return loss is $25 \mathrm{~dB}$ (figure 7, software, $40 \mathrm{~dB}$ ) and the insertion loss is $0.1 \mathrm{~dB}$ (figure 7, software, $0.08 \mathrm{~dB}$ ) at $2.45 \mathrm{GHz}$ frequency. It is noted from figure $13 \mathrm{e}$ (measured result for the microwave vacuum window), that the return loss is $21 \mathrm{~dB}$ (figure 8 , software, $75 \mathrm{~dB}$ ) and the insertion loss is $0.3 \mathrm{~dB}$ (figure 8 , software, $0.0 \mathrm{~dB}$ ) at $2.45 \mathrm{GHz}$ frequency.

All the microwave components were integrated with glass water load at the end for the high power characterization of the microwave components. This microwave line was energized and tested for $2 \mathrm{~kW}$ of microwave power at $2.45 \mathrm{GHz}$ frequency. The performance of the microwave line was quite satisfactory. The radio frequency microwave radiation survey (using radiation survey meter Model : HI 1501, Make : M/s Richardson Electronics Pvt. Ltd., USA) was carried out. A maximum radiation leakage of $2-3 \mathrm{~mW} / \mathrm{cm}^{2}$ was observed around microwave vacuum window and the high voltage break. The radiation level was found to be well within the permissible limit. Further, to avoid any radiation leakage from the dielectric portion a metallic cover is wrapped externally at the joint.

\section{Performance of the microwave system}

After the low power characterization these microwave components were integrated with $2 \mathrm{~kW}$ glass-water load for high power characterization before connecting them to the actual load i.e., with the plasma chamber. A 3D-view of the high power characterization of the microwave system test set-up is shown in figure 14. The variation of magnetron output power versus cathode current was measured to be linear with a slope of $2.73 \mathrm{~W} / \mathrm{mA}$. The variation of magnetron output power with cathode current is shown in figure 15 . The error in the measurement is considered $\sim 5 \%$. The required components were water like magnetron, isolator and glass water load for the continuous operation of the magnetron source. The reflected power was minimized during the course of experiments with the tuning stubs of the three-stub tuner.

The base vacuum in the plasma chamber was maintained $\sim 10^{-6}$ mbar using a 400 liter/sec turbo-molecular pump. Experimental gas (nitrogen, argon, or hydrogen) was fed to the plasma chamber through a mass flow controller and maintained at $10^{-5}-10^{-3}$ mbar pressure. The plasma chamber was excited at 300-1000 $\mathrm{W}$ of microwave power and stable plasma was produced. The plasma was seen from outside using quartz window. It was characterized by using electrostatic Langmuir probe current-voltage curve. The plasma density and electron temperature were calculated using standard relations. On average, plasma density of $\sim 5 \times 10^{11} \mathrm{~cm}^{-3}$ and electron temperature of $\sim 13 \mathrm{eV}$ was obtained. With the use of this microwave system, we have extracted $8 \mathrm{~mA}$ proton beam current at $25 \mathrm{keV}$ beam energy. The results have been reported earlier in ref. (Jain et al 2006, 2007, 2013).

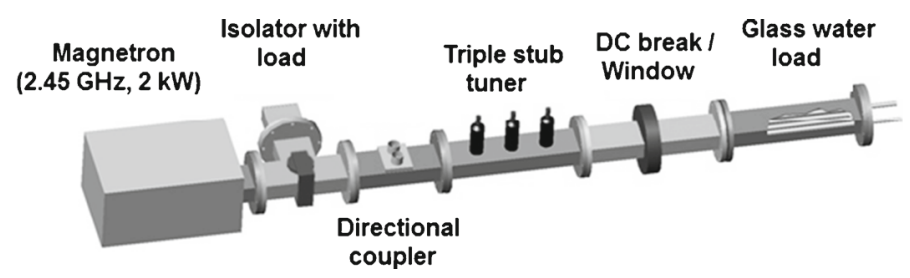

Figure 14. A $3 \mathrm{D}$-view of the high power characterization of the microwave system test set-up. 


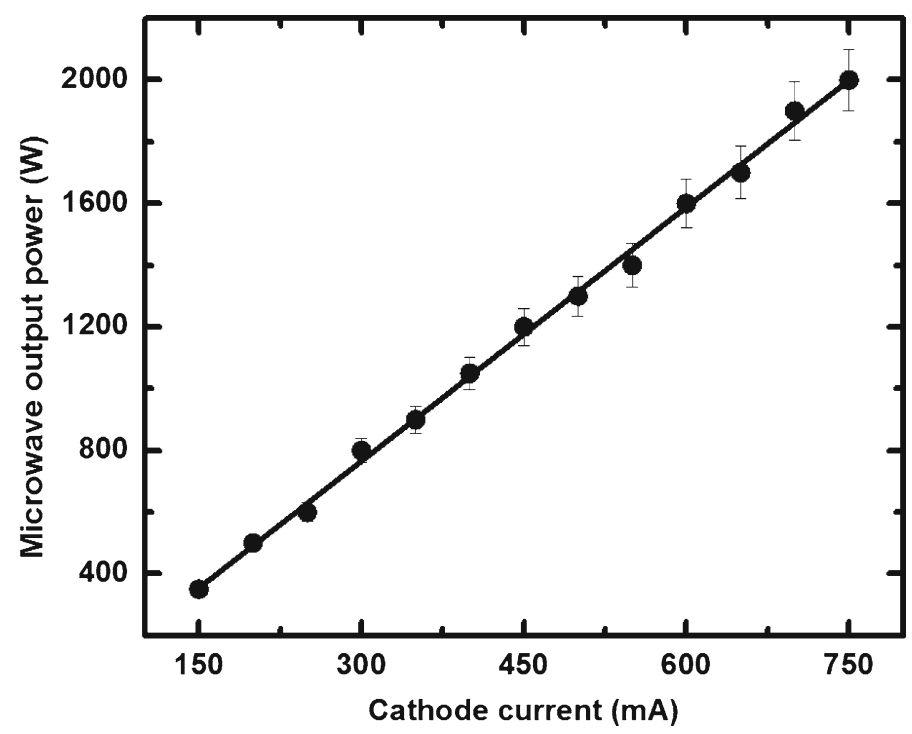

Figure 15. The variation of the magnetron output power with cathode current (the solid curve is for visual aid only).

\section{Conclusions}

The integrated microwave system has been successfully used to produce dense plasma for nitrogen/argon/hydrogen gas at different operation regimes. The electron cyclotron resonance source is in operation and we have extracted around $8 \mathrm{~mA}$ proton beam current at $25 \mathrm{keV}$ beam energy. This has validated the design and development of the microwave system at $2.45 \mathrm{GHz}$ frequency and power up to $2 \mathrm{~kW}$ continuous wave. The integrated microwave system with the plasma chamber was in safe operation towards the permissible limit of microwave radiation leakage to environment. In future Phase-II operations, 90 degree E-plane bend (water-cooled) is planned to use to prevent damage of microwave vacuum window from back-streaming of the electrons.

\section{References}

Baskaran R, Jain S K and Ramamurthi S S 1992a An S-band high power waveguide system for $20 \mathrm{MeV}$ injector Microtron. Indian J. Pure Appl. Phys. 30: 23-32

Baskaran R, Jain S K and Ramamurthi S S 1992b E-plane horn excitation of slow wave structures for obtaining high density electron cyclotron resonance plasmas. Rev. Sci. Instrum. 63: 1939-1944

Baskaran R, Jain S K and Ramamurthi S S 1996 A compact coaxial electron cyclotron resonance plasma source. Rev. Sci. Instrum. 67: 1243-1245

Baskaran R 1997 Double window configuration as a low cost microwave waveguide window for plasma applications. Rev. Sci. Instrum. 68: 4424-4426

Celona L, Ciavola G and Gammino S 1998 Study of microwave coupling ECR ion sources and microwave ion sources. Rev. Sci. Instrum. 69: 1113-1115

Celona L, Gammino S, Ciavola G, Chines F, Marletta S and Messina E 2000 Ionization of efficiency measurements with the microwave discharge ion source MIDAS, EPAC-2000

Chapman B 1980 Glow discharge process. New York: John Wiley \& Sons 
Chatterjee R 1984 Elements of microwave engineering. New Delhi: East-West

Collin R E 1966 Foundations for microwave engineering. New York: Mc-Graw-Hill

Downs H, Matthews P and Sanborn W 2008 Waveguide directional couplers for high vacuum applications EPAC-2008

Gammino S, Celona L, Ciavola G, Castro M, Chines F, Marletta S, Melin G, Brian P, Girard A, Ludwig P, Seyfert P and Guillaume D 1999 Proceedings of the $14^{\text {th }}$ Int. Workshop on ECR Sources

Ganguli A, Baskaran R, Naidu P A and Raju G V R 1989 High power microwave line with arbitrary impedance matching capability for plasma applications. Rev. Sci. Instrum. 60: 244-248

Ginzton E D 1957 Microwave measurements. New York: Mc-Graw-Hill

Harvey A F 1963 Microwave engineering. New York: Academic

http://www.cst.de CST Microwave Studio software version 5.1

http://www.lns.infn.it

Jain S K, Jain A and Hannurkar P R 2004 Indigenous development of a low cost high power $2 \mathrm{~kW}$ (CW) microwave system. Indian J. Pure Appl. Phys. 42: 896-901

Jain S K, Jain A, Deepak Sharma and Hannurkar P R 2006 Acquisition and analysis of Langmuir probe characterization for electron cyclotron resonance plasma. Indian J. Phys. 80: 1011-1014

Jain S K, Akhilesh Jain, Hannurkar P R and Kotaiah S 2007 Characterization of plasma parameters, first beam results and status of electron cyclotron resonance source. Rev. Sci. Instrum. 78: 053301

Jain S K, Tayyab M, Bagchi S, Chakera J A and Naik P A 2013 Characterization of proton beam emission from an electron cyclotron resonance ion source. Nucl. Instr. Meth. Phys. Res. A 708: 51-55

Krestschmer K, Matl K, Lorenz G and Kessler I 1980 Solid State Technol. 33: 53

Marcuvitz N 1951 Waveguide Handbook. New York: Mc-Graw-Hill

Matsuda K and Tanjyo M 1996 Ion sources for implantation applications. Rev. Sci. Instrum. 67: 901-904

Miyamura M, Tsukakoshi O and Komiya S 1982 A 26-cm electron cyclotron resonance ion source for reactive ion beam etching of $\mathrm{SiO}_{2}$ and Si. J. Vac. Sci. Technol. 20: 986-988

Montgomery C G 1947 Techniques of Microwave Measurements. New York: Mc-Graw-Hill

Nikiforov S, Solnyshkov D, Voronin G and Solnyshkov A 1994 Development of an electron cyclotron resonance ion source for accelerators and plasma processing applications EPAC-1994: 1427-1429

Pozar D M 2005 Microwave Engineering. New York: John Wiley \& Sons

Sakudo N, Tokigachi K, Koike H and Kanumata I 1977 Mcrowave ion source. Rev. Sci. Instrum. 48: 762-766

Sherman J, Arvin A, Hansborough L, Hodgkins D, Meyer E, Schneider J D, Stevens R R, Thuot M and Zaugg T 1998 Development of a $130 \mathrm{~mA}, 75 \mathrm{kV}$ high voltage column for high density dc proton injectors. Rev. Sci. Instrum. 69: 1017-1019

Sitar Z, Paisley M J, Smith D K and Davis R F 1990 Design and performance of an electron cyclotron resonance plasma source for standard molecular beam epitaxy applications. Rev. Sci. Instrum. 61: $240-2411$

Smith T L, Berg S, Grelick A and Waldschmidt G 2003 Bidirectional coupler optimization in WR-284 type waveguide. PAC-2003

Tani Y, Aoi Y and Kamijo E 1998 Composition and crystal structure of carbon nitride films prepared by the electron cyclotron resonance plasma sputtering method. Appl. Phy. Lett. 73: 1652-1654

Taylor T and Wills J S C 1991 A high current low emittance dc electron cyclotron resonance proton source. Nucl. Instr. Meth. Phys. Res. A 309: 37-42

Taylor T 1992 High current dc microwave ion sources. Rev. Sci. Instrum. 63: 2507-2512

Taylor T and Mouris J F 1993 An advanced high current low emittance dc microwave proton source. Nucl. Instr. Meth. Phys. Res. A 336: 1-5 